\section{Tremor essencial em guardas de endemias expostos a agrotóxicos: estudo caso-controle}

\author{
Essential tremor in endemic disease control \\ agents exposed to pesticides: a case-control \\ study
}

Temblor esencial en empleados públicos del
sector de vigilancia y control de endemias
expuestos a pesticidas: estudio caso-control

\section{Resumo}

Tremor é o distúrbio do movimento mais frequente na população, e pode estar associado a exposição a agrotóxicos. O objetivo foi avaliar a chance de tremor essencial em 442 guardas de endemias do Estado do Rio de Janeiro, Brasil, expostos a agrotóxicos. Foram selecionados 51 casos e 204 controles (1:4). Todos os participantes responderam a um questionário sobre aspectos sociodemográficos, ocupacionais e toxicológicos. A influência da exposição a agrotóxicos sobre o desenvolvimento do tremor foi estimada por regressão logística não condicional, ajustada por covariáveis selecionadas. A idade média da população estudada foi de $49(D P=7)$ anos, sendo a diferença entre casos ( média $=50,8 ; D P=6,9)$ e controles (média $=48,5 ; D P=6,9)$ estatisticamente significativa $(p=0,03)$. Além disso, aqueles com 16 a 16,9 anos de aplicação de agrotóxicos foram os que estiveram sob maior chance de apresentar a doença (OR ajustada = 4,60; IC95\%: 1,29-16,41). Nossos resultados sugerem que o período entre 16 e 16,9 anos de aplicação de agrotóxicos teve impacto importante para o desenvolvimento dessa doença.

Tremor Essencial; Agroquimicos; Compostos Organofosforados
Marlos Fábio Alves de Azevedo 1

Armando Meyer 2

doi: 10.1590/0102-311X00194915

\author{
Correspondência \\ M. F. A. Azevedo \\ Centro de Estudos da Saúde do Trabalhador e Ecologia \\ Humana, Escola Nacional de Saúde Pública Sergio Arouca, \\ Fundação Oswaldo Cruz. \\ Av. Leopoldo Bulhões 1480, Rio de Janeiro, RJ 21041-210, \\ Brasil. \\ mfaazevedo@ensp.fiocruz.br \\ 1 Escola Nacional de Saúde Pública Sergio Arouca, Fundação \\ Oswaldo Cruz, Rio de Janeiro, Brasil. \\ 2 Instituto de Estudos em Saúde Coletiva, Universidade Federal \\ do Rio de Janeiro, Rio de Janeiro, Brasil.
}




\section{Introdução}

O Brasil é o maior consumidor de agrotóxicos do mundo. Esse posto, atingido em 2008, em grande parte à custa da indústria agrícola, movimentou, entre 2010 e 2011, uma receita de US\$ 8,5 bilhões e um consumo de 936 mil toneladas, o que representou 19\% do mercado global de agrotóxicos nesse período 1,2 . Os principais grupos profissionais expostos aos agrotóxicos são os trabalhadores do setor agropecuário, saúde pública, firmas desinsetizadoras, transporte e comércio, indústrias de formulação e síntese e área veterinária ${ }^{3}$. O controle de vetores urbanos é uma importante fonte de contaminação ocupacional e ambiental, utilizando os mesmos princípios ativos de agrotóxicos. Os setores público e privado atuam em diversos ambientes, sendo responsáveis pela manipulação, transporte, inutilização e descarte de embalagens 4,5.

A exposição crônica a agrotóxicos pode acometer inúmeros sistemas. Doenças hematológicas, dermatológicas, pulmonares, neurológicas, câncer, malformações congênitas, entre outras podem estar associadas a essa exposição 3 . O tremor é o distúrbio do movimento mais frequente na população em geral, sendo que o tremor essencial é uma das doenças neurológicas de maior prevalência 6,7. Essa prevalência na população geral é estimada em torno de $0,4 \%$, podendo variar conforme sexo e etnia, e tende a aumentar com a idade, podendo chegar a $6,3 \%$ entre indivíduos $\geq 65$ anos e $21,7 \%$ entre aqueles com $\geq 95$ anos 8,9. Já a taxa de incidência foi estimada entre 23,7 e 616 por 100 mil 10. Um estudo brasileiro realizado em uma cidade do interior de Minas Gerais observou uma prevalência de 7,4\% de tremor essencial em indivíduos com $\geq 64$ anos 11 .

As conexões entre as regiões do córtex cerebral e subcortical, assim como os sistemas piramidal e extrapiramidal, são parte obrigatória para a compreensão dos mecanismos envolvidos no tremor essencial. As áreas motoras 4 e 6 de Brodmann, localizadas na região frontal do córtex cerebral, associadas, entre outras funções, à noção de posição e movimento do corpo comunicam-se com as regiões subcorticais por meio de complexos circuitos 12. Dois dos principais circuitos são o córtico-estriado-tálamo-cortical e o circuito córtico-ponto-cerebelo-rubro-cortical 13. Por sua vez, o estriado é composto pelos núcleos caudado e putâmen 14. Essas e outras numerosas outras estruturas fazem parte dos núcleos da base cerebral. Esses circuitos juntamente com o triângulo de Guillain-Mollaret responderão pelas bases fisiológicas do tônus muscular, equilíbrio e coordenação motora nos seres humanos 12. O mau funcionamento dessas estruturas irá propiciar inúmeros quadros neurológicos relacionados ao amplo espectro dos distúrbios de movimento.

Ainda que atualmente os sistemas motores possam ser classificados como lateral e medial, historicamente e de forma bastante superficial, o sistema piramidal é responsável pelos movimentos voluntários, e o extrapiramidal pelos movimentos automáticos 13,14. Esses sistemas trabalham em conjunto, regulando inúmeras ações. O triângulo de Guillain-Mollaret é parte do segundo circuito. É um subcircuito composto pelo núcleo rubro (mesencéfalo), feixe central do tegmento, núcleo olivar inferior (ponte), núcleo denteado (cerebelo), retornando ao núcleo rubro ${ }^{12}$. São conexões que, dentro da estrutura anatômica, lembram um formato triangular.

Estudos em modelo animal observaram quadros de tremor postural após a estimulação do núcleo olivar inferior 15. Em indivíduos portadores de tremor essencial, foram observadas alterações histopatológicas na região cerebelar, caracterizada por perda e edema axonal das células de Purkinje (células torpedo) e no tronco cerebral, incluindo a presença de corpúsculos de Lewy ${ }^{16}$. Essas alterações também não foram encontradas em todos os portadores da doença e, em uma parcela de pacientes, não foi observada qualquer alteração. A presença do corpúsculo de Lewy e a possibilidade de sobreposição entre o tremor essencial e a doença de Parkinson falariam a favor de uma doença degenerativa, mas ainda não há consenso sobre isso 16,17 .

Quatro dos principais neurotransmissores envolvidos nesses sistemas são o ácido gama-amino-butírico (GABA), a dopamina, a acetilcolina e o ácido glutâmico. Eles atuam no controle excitatório e inibitório desses circuitos. É possível que receptores beta-adrenérgicos também estejam envolvidos, todavia o sistema gabaérgico tem papel importante na fisiopatogenia do tremor essencial, haja vista que as principais opções para o tratamento do tremor essencial incluem medicamentos com esse mecanismo de ação 18,19 .

Os grupos químicos de agrotóxicos organoclorados, organofosforados e piretroides possuem mecanismos próprios de neurotoxicidade. Os inseticidas organoclorados alteram a eletrofisiologia 
da membrana neuronal e suas enzimas relacionadas com a Na+-ATPase e K+-ATPase, modificando a cinética do fluxo dos íons $\mathrm{Na}+\mathrm{e} \mathrm{K}+20,21$. O DDT (diclorodifeniltricloroetano) atua no prolongamento da abertura dos canais de sódio. Quando esses canais estão fechados, há pouca ou nenhuma ação. Já o lindano e os ciclodienos atuam na inibição de fluxo dos canais de cloro regulados pelo GABA 20,21. Os inseticidas organofosforados atuam primariamente na inibição da acetilcolinesterase (AChE), acumulando acetilcolina nos terminais pré-sinápticos 20,21. O acúmulo de acetilcolina na fenda sináptica hiperestimula receptores colinérgicos do tipo muscarínico e nicotínico. Também há a inibição da butirilcolinesterase (BuChE), conhecida como falsa colinesterase, o que também contribui para a deflagração do processo 20,21. Os piretroides ligam-se à subunidade alfa do canal de sódio e lentificam a abertura e o fechamento do canal de sódio, mantendo-o em um estado de hiperexcitabilidade constante. As diferenças no tempo de abertura dos canais de sódio é que serão a base de diferenciação entre os dois tipos de reações possíveis de ocorrer nesse grupo químico 20,21. A reação tipo I ou síndrome $\mathrm{T}$ afeta os canais de sódio, causando descargas neuronais repetidas e um período maior de repolarização 20,21. Clinicamente, caracteriza-se por agressividade, aumento da resposta aos estímulos externos, tremores generalizados ou prostração 20,21. A reação tipo II produz maior atraso na inatividade do canal de sódio, levando à persistente despolarização da membrana, sem descargas repetitivas 20,21. Clinicamente, caracteriza-se por hipersialorreia, tremor, coreoatetose e crises convulsivas 20,21.

Já os biolarvicidas têm ação na produção de endotoxinas proteicas que, quando ingeridas pela larva do mosquito, provocam a sua morte 22 . A benzoilureia inibe o crescimento dos insetos, impedindo a formação da quitina. Esse é um elemento essencial do exoesqueleto com função de proteção mecânica. Caso consiga eclodir, induz à malformação e à esterilidade nos insetos adultos 23.

Estudos em modelo animal in vivo e in vitro verificaram a ação dos agrotóxicos em diversos neurotransmissores envolvidos nesses circuitos cerebrais. Há um mecanismo de autorregulação, com o objetivo de manter o seu perfeito funcionamento. Apesar de a via gabaérgica ter um papel potencial na fisiopatogenia do tremor essencial, seguramente não é o único mecanismo envolvido. $O$ tremor essencial, assim como a doença de Parkinson, doença de Alzheimer e a esclerose lateral amiotrófica, são doenças neurológicas crônicas. A indução de doenças neurológicas e outras doenças crônicas pelos agrotóxicos tem sido aventada por meio de diversos mecanismos.

Os inseticidas organofosforados são metabolizados inicialmente pelo citocromo P-450 (CYP450) através da dessulfuração oxidativa, em que há oxidação de $\mathrm{P}=\mathrm{S}$ (forma tions) para $\mathrm{P}=\mathrm{O}$ (forma oxons), resultando na formação de metabólitos com maior toxicidade 20,21. A paraoxonase-1 (PON1) é uma das principais fosfodiesterases responsáveis por hidrolizar os oxons. Outras co-enzimas do complexo CYP450 envolvidos na metabolização dos oxons são a CYP2B6, CYP2C19 e CYP3A4 24. É provável que variações genéticas dessas enzimas metabolizadoras de xenobióticos possam alterar sua atividade catalítica e aumentar a concentração de oxons, tanto no soro quanto nos tecidos alvo. A presença de polimorfismos da PON1 na região de codificação (PON1Q192R e PON1L55M) resulta em menor atividade catalítica e redução dos níveis proteicos 24 . A glutotiona-S-transferase (GST), a $\mathrm{BuChE}$ e as carboxilesterases (CEs) também possuem importante papel catalítico das oxons e, assim como a GST, polimorfismos genéticos podem influenciar nesse processo 25 .

A predisposição genética ao tremor essencial é um fator que tem sido estudado ao longo dos anos. A história familiar pode ser encontrada em uma prevalência com variações extremas. A presença do gene LINGO1 em diversas populações está associada a maior chance em desenvolver essa doença 26. Em modelo animal, a inibição do LINGO1 promoveu a persistência de neurônios e oligodendrócitos, a regeneração axonal, a diferenciação oligodendrocitária, a remielinização e a melhora funcional dos ratos 26. Independente das discussões sobre os polimorfismos do LINGO1 e da sua associação com doença familiar ou esporádica, este parece ser o gene mais associado à doença.

Está bem estabelecido o potencial neurotóxico da via colinérgica em intoxicações agudas por organofosforados. Entretanto, estudos têm apontado que alguns organofosforados podem causar neurotoxicidade, mesmo em doses baixas o suficiente para não ativarem a via colinérgica e seus metabólitos oxons 24. Estudos in vitro indicam que o diazinon-oxon é capaz de reduzir o número de dendritos, enquanto o clorpirifós-oxon inibe a síntese de DNA em células germinativas de glioma e rompe a diferenciação celular glial, afetando a integridade da rede de microtúbulos 24 . Esse efeito foi observado em concentração nanomolar, que é muito menor do que o necessário para inibir significativamente a atividade da enzima $\mathrm{AChE}$ 24. Por outro lado, o padrão de expressão das variações 
não enzimáticas da $\mathrm{AChE}$ tem um papel na neurotoxicidade pelos organofosforados. As isoformas mais abundantes são a AChE-S (enzima de membrana multimérica) e a isoforma monomérica solúvel "readthrough" (AChE R). A primeira teria capacidade neurotóxica e a segunda, atividade reparadora e protetora 24.

A mitocôndria tem sido considerada um provável alvo no processo neurodegenerativo causado pela exposição crônica e em níveis baixos a organofosforados 24,27. O organofosforado pode elevar a recaptação do cálcio mitocondrial que compromete a função dos complexos I e II e diminui a transferência de elétrons para o citocromo oxidase (complexo IV) 24,27. Esse processo pode causar a peroxidação lipídica, elevar a proteína carbonil, estimular a formação de 8-hidroxideoxiguanosina e a oxidação proteica e do DNA mitocondrial. Esses eventos afetam a síntese de ATP 24,27. Como resultado da quebra da capacidade transmembrana mitocondrial, o citocromo c é liberado pela mitocôndria para o citosol e diversas caspases são ativadas, levando ao estresse oxidativo, e, consequentemente, à morte por apoptose celular 24,27 .

Danos genéticos e modificações epigenéticas estão mais associadas ao câncer do que ao desenvolvimento de doenças neurológicas. Coletivamente, a exposição crônica a agrotóxicos em doses baixas, a metabolização pela via não colinérgica, os polimorfismos genéticos das enzimas que degradam os oxons, a predisposição genética ao tremor essencial, o comprometimento mitocondrial levando ao estresse oxidativo e a consequente apoptose celular de neurônios gabaérgicos podem contribuir para o desenvolvimento do tremor essencial.

O tremor essencial acomete mãos e antebraços, mas pode se manifestar em outras partes do corpo 17,28. A frequência do tremor essencial varia entre $4 \mathrm{~Hz}$ e $12 \mathrm{~Hz}$, e é inversamente proporcional à idade com pacientes mais velhos, exibindo frequências mais baixas 17,28. A presença de história familiar varia conforme o estudo, podendo chegar a até $80 \%$ em alguns levantamentos. Existem diversos genes já identificados e potencialmente associados à doença 26. Em 2009, a descoberta de uma variação do gene LINGO1 foi associada ao tremor essencial na Islândia. Tal associação também foi observada em populações na Áustria, na Alemanha e nos Estados Unidos 26. Clinicamente, o tremor essencial tende a ter uma evolução lenta durante os anos, e algumas comorbidades podem estar associadas. Dentre elas, têm sido descritas alterações cognitivas, transtornos de humor e da marcha 16 . Alguns estudos observaram que indivíduos com tremor essencial têm quatro vezes mais chance de desenvolver parkinsonismo 16. São doenças distintas com mecanismos e patologias diferenciadas, entretanto é frequente haver sobreposição dessas doenças, o que torna o seu diagnóstico e tratamento desafiadores.

A espectroscopia cerebelar por ressonância magnética (RM), a tomografia por emissão de pósitrons (PET-Scan), a ultrassonografia transcraniana, a eletroneuromiografia e o acelerômetro não foram capazes de predizer o diagnóstico do tremor essencial 28,29. Ainda continua a ser um quadro neurológico de diagnóstico eminentemente clínico. Fatores ambientais têm sido associados ao tremor essencial. Alcaloides beta-carbolínicos (harmine e harmane) e chumbo têm sido associados à doença 27,30. Estudos experimentais e clínicos envolvendo os inseticidas dos grupos químicos organoclorado, organofosforado e piretroide também parecem estar associados ao tremor 31,32,33,34,35,36. Em agricultores norte-americanos, o Agricultural Health Study observou uma prevalência de 5\% de tremor em uma população de 18.782 trabalhadores; ressalve-se que eram sinais e sintomas, e não diagnóstico de tremor essencial 37 . No entanto, ainda pouco se sabe sobre a relação entre a exposição a agrotóxicos e essa doença.

O objetivo deste estudo foi avaliar a associação entre exposição crônica a agrotóxicos e presença de tremor essencial entre guardas de endemias do Estado do Rio de Janeiro, Brasil.

\section{Metodologia}

\section{Desenho de estudo}

Trata-se de um estudo caso-controle realizado a partir do atendimento de 442 guardas de endemia oriundos da Fundação Nacional de Saúde (Funasa), também conhecidos como agentes de combate às endemias. Lotados em diversos municípios do Estado do Rio de Janeiro, buscaram atendimento no Ambulatório de Neurotoxicologia Ocupacional e Ambiental do Centro de Estudos da Saúde do 
Trabalhador e Ecologia Humana, Escola Nacional de Saúde Pública Sergio Arouca, Fundação Oswaldo Cruz (CESTEH/ENSP/Fiocruz), no período entre agosto de 2010 e setembro de 2012.

\section{Casos e controles}

Os casos de tremor essencial foram diagnosticados seguindo os critérios estabelecidos pela International Parkinson and Movement Disorder Society 28. Inicialmente, 95 trabalhadores foram diagnosticados com a doença, entretanto 44 foram excluídos por tratar-se de tremor secundário ou por não terem completado todo o protocolo, resultando em um número final de 51 casos.

O grupo controle foi constituído a partir dos demais 347 guardas de endemias sem tremor. Desses, 45 foram excluídos por apresentarem doença neurológica prévia (5), doença que fizesse parte dos critérios de exclusão (11) ou por não terem completado o protocolo (29). Dos 302 trabalhadores remanescentes, foram selecionados aleatoriamente 4 controles para cada caso, perfazendo um total de 51 casos e 204 controles (1:4). Casos e controles tiveram origem a partir do estudo de prevalência de tremor essencial realizado entre 2010 e 2012 (dados ainda não publicados).

As comorbidades incluídas nos critérios de exclusão foram os seguintes: presença de história de intoxicação aguda que necessitasse de internação hospitalar, doença neurológica prévia e condições clínicas e/ou medicamentosas que fossem fatores de confundimento como diabetes (associada à neuropatia periférica), hipotireoidismo ou hipertireoidismo, hipovitaminose B12, alcoolismo, HIV/AIDS, sífilis e hanseníase.

Casos e controles foram submetidos a um protocolo de estudo constituído por exame neurológico, questionário contendo variáveis referentes aos aspectos socioeconômico, demográfico, clínico, ocupacional e toxicológico, e exames laboratoriais para descartar doenças endócrina, metabólica, infecciosa e deficiência nutricional. Para os casos com diagnóstico inicial de tremor essencial, foi realizada tomografia computadorizada de crânio, a fim de descartar causas secundárias de tremor. Todos os pacientes com suspeita de tremor essencial foram avaliados, pelo menos, em dois momentos distintos, a fim de descartar outros diagnósticos diferenciais como tremor fisiológico exacerbado, tremor psicogênico ou parkinsonismo em fase inicial. Um banco de dados foi criado a partir do protocolo de atendimento dos guardas de endemias atendidos.

\section{Avaliação da exposição a agrotóxicos}

Casos e controles responderam a questionário contendo perguntas sobre o histórico de aplicação de agrotóxicos, como a frequência de aplicação (dias por semana), a duração de aplicação (horas por dia) e o tempo de aplicação de agrotóxicos (em anos). Essas variáveis foram utilizadas para formular dois indicadores de exposição acumulada a agrotóxicos. O primeiro indicador foi a carga acumulada por grupo químico, em que a intensidade de aplicação foi estimada por meio da quantidade mínima aplicada (QMA). Esse indicador foi calculado, por trabalhador, da seguinte forma: anos de aplicação $\mathrm{x}$ frequência de aplicação x concentração do agrotóxico específico (para os agrotóxicos de mesma classe química), tendo como unidade quilograma $(\mathrm{kg})$ de agrotóxicos aplicados. Foram considerados, em média, 220 dias trabalhados por ano e uma frequência semanal de aplicação variável conforme os dados da anamnese. A concentração do inseticida/larvicida utilizada para calcular o índice foi aquela registrada no rótulo da embalagem.

O segundo indicador de exposição foi denominado carga acumulada global. Esse indicador foi calculado, por trabalhador, da seguinte forma: anos de aplicação x frequência de aplicação x horas trabalhadas por dia. Foram consideradas, em média, 50 semanas trabalhadas por ano e uma frequência semanal de aplicação variável, conforme os dados obtidos no questionário, multiplicada pelo tempo de aplicação diária (em horas).

\section{Análise estatística}

A análise descritiva das variáveis, para melhor apresentação das características da amostra, envolveu o cálculo das frequências das variáveis nominais e das medidas de tendência central e de dispersão das variáveis contínuas (mínimo, máximo, média, desvio padrão). As variáveis avaliadas como poten- 
cialmente preditoras foram sexo, idade, tempo de aplicação, início da doença, tempo de aplicação para início da doença, quantidade de agentes tóxicos utilizados no período, coexposição ocupacional a metais e/ou solventes, tabagismo, etilismo, carga acumulada por grupo químico e carga acumulada global. Para tal, foram utilizados os testes t de Student para amostras independentes, teste de MannWhitney U e o teste de qui-quadrado. Por fim, as razões de chance (OR) de tremor essencial entre casos e controles foram estimadas por meio da regressão logística não condicional ajustada pelas covariáveis selecionadas, tanto para a carga acumulada global (horas-aplicadas) quanto para a carga acumulada por grupo químico. Para as análises bivariadas, o nível de significância estatística adotado foi de 95\% (p $\leq$ 0,05). Para as OR, foram estimados também os intervalos de 95\% de confiança (IC95\%). O pacote estatístico utilizado foi o SPSS 13.0 for Windows (SPSS Inc., Chicago, Estados Unidos).

\section{Aspectos éticos}

Este estudo foi aprovado pelo Comitê de Ética em Pesquisa da ENSP/Fiocruz (parecer no 440.972) em 31 de outubro de 2013.

\section{Resultados}

A Tabela 1 apresenta as principais características da população de casos e controles. A frequência de tremor essencial entre homens e mulheres foi de $73 \%$ e $27 \%$, respectivamente. A idade média da população estudada foi de $49(\mathrm{DP}=7)$ anos, sendo a diferença entre casos (média = 50,8; DP = 6,9) e controles (média $=48,5 ; \mathrm{DP}=6,9)$ estatisticamente significativa $(\mathrm{p}=0,03)$. O tempo médio de aplicação foi de 18 ( $\mathrm{DP}=5,7)$ anos e o número médio de horas aplicadas foi de 36.021 (DP = 18.318). Não foi observada associação significativa entre as variáveis sociodemográficas e tremor essencial (Tabela 1).

A Tabela 2 apresenta as estimativas das OR de tremor essencial em função do número de horas aplicadas de agrotóxicos. Não foi observada diferença significativa segundo tremor essencial e o gradiente dose-resposta. Já as estimativas das OR de tremor essencial entre guardas de endemias em função da quantidade de agrotóxicos aplicada podem ser observadas na Tabela 3. A OR entre tremor essencial e o gradiente dose-resposta nos trabalhadores que aplicaram tanto organofosforado em bombas quanto na forma granulada (temefós) também não foi significativa. Outro grupo químico largamente utilizado pelos trabalhadores foi a benzoilureia, cuja aplicação também não apresentou diferença significativa, bem como o uso de inseticidas das classes organoclorado, piretroide e biológico.

A Tabela 4 mostra as estimativas de tremor essencial em função do tempo de aplicação de agrotóxicos. Trabalhadores que aplicaram agrotóxicos por 16 a 16,9 anos foram aqueles que apresentaram a maior chance para a doença, mesmo quando ajustado por sexo e idade (OR ajustada = 4,60; IC95\%: $1,29-16,41)$ ou por sexo, idade, etilismo, tabagismo e coexposição ocupacional a metais e/ou solventes (OR ajustada = 4,91; IC95\%: 1,34-18,03).

\section{Discussão}

São poucos os estudos que avaliaram a relação entre tremor e exposição a agrotóxicos. O estudo sobre a saúde dos agricultores norte-americanos realizado nos estados de Iowa e Carolina do Norte, entre 1993 a 1997, ainda é a principal referência no que se refere a essa relação 37. Baseado em questionários autoaplicados, estimou uma prevalência de tremor em $5 \%$ daqueles trabalhadores 37 . Após ajuste pelas covariáveis selecionadas, foi encontrada OR elevada de tremor em agricultores expostos a organofosforado, organoclorado e fumigantes 37 , embora o tremor como sinal clínico não necessariamente significa tratar-se de tremor essencial.

O estudo realizado em agricultores canadenses também observou uma OR elevada de tremor naquela população ${ }^{38}$. Apesar do possível confundimento devido à coexposição a metais (chumbo e mercúrio), aqueles agricultores apresentaram maior chance de desenvolver tremor quando comparado a dois grupos controles 38 . Por outro lado, o estudo realizado em controladores de pragas e vetores de empresas privadas do Estado da Carolina do Norte não observou associação significativa 39. 
Tabela 1

Características principais da população de casos e controles.

\begin{tabular}{|c|c|c|c|c|c|}
\hline \multirow[t]{2}{*}{ Variáveis } & \multicolumn{2}{|c|}{ Casos } & \multicolumn{2}{|c|}{ Controles } & \multirow[t]{2}{*}{ OR (IC95\%) * } \\
\hline & $\mathbf{n}$ & $\%$ & $\mathbf{n}$ & $\%$ & \\
\hline \multicolumn{6}{|l|}{ Idade (anos) } \\
\hline$\leq 41$ & 5 & 9,8 & 27 & 13,2 & \\
\hline $42+$ & 46 & 90,2 & 177 & 86,8 & $1,40(0,51-3,85)$ \\
\hline \multicolumn{6}{|c|}{ Tempo de aplicação (anos) } \\
\hline$\leq 10$ & 1 & 2,0 & 20 & 9,8 & \\
\hline $11+$ & 50 & 98,0 & 184 & 90,2 & $5,45(0,71-41,49)$ \\
\hline \multicolumn{6}{|c|}{ Agentes tóxicos } \\
\hline$\leq 3$ & 8 & 15,7 & 52 & 25,5 & \\
\hline $4+$ & 43 & 84,3 & 152 & 74,5 & $1,84(0,81-4,17)$ \\
\hline \multicolumn{6}{|c|}{ Coexposição ocupacional (metais e/ou solventes) } \\
\hline Não & 38 & 74,5 & 171 & 83,8 & \\
\hline Sim & 13 & 25,5 & 33 & 26,2 & $1,77(0,85-3,69)$ \\
\hline \multicolumn{6}{|l|}{ Etilismo } \\
\hline Não & 21 & 41,2 & 114 & 55,9 & \\
\hline Sim & 30 & 58,8 & 90 & 44,1 & $1,81(0,97-3,37)$ \\
\hline \multicolumn{6}{|l|}{ Tabagismo } \\
\hline Não & 47 & 92,2 & 179 & 87,7 & \\
\hline Sim & 4 & 7,8 & 25 & 22,3 & $0,61(0,20-1,84)$ \\
\hline \multicolumn{6}{|c|}{ Carga acumulada global (hora-aplicada) } \\
\hline$\leq 33.000$ & 22 & 43,1 & 107 & 52,5 & \\
\hline $33.001+$ & 29 & 66,9 & 97 & 47,5 & $1,45(0,78-2,70)$ \\
\hline
\end{tabular}

IC95\%: intervalo de 95\% de confiança; OR: razão de chances.

* Teste $\chi^{2}$.

Tabela 2

Razão de chances (OR) de tremor essencial entre guardas de endemias, segundo horas aplicadas de agrotóxicos.

\begin{tabular}{|c|c|c|c|c|c|c|}
\hline \multirow[t]{2}{*}{ Carga acumulada global (hora-aplicada) } & \multicolumn{2}{|c|}{ Casos } & \multicolumn{2}{|c|}{ Controles } & \multirow[t]{2}{*}{ OR $(\mathrm{IC} 95 \%) *$} & \multirow[t]{2}{*}{ OR $($ IC95\%) ** } \\
\hline & $\mathbf{n}$ & $\%$ & $\mathbf{n}$ & $\%$ & & \\
\hline$\leq 23.000$ & 13 & 25,5 & 51 & 25,0 & \multicolumn{2}{|c|}{ Referência } \\
\hline $23.001-33.000$ & 10 & 19,6 & 54 & 26,5 & $1,22(0,44-3,40)$ & $1,17(0,41-3,32)$ \\
\hline $33.001-48.000$ & 15 & 29,4 & 49 & 24,0 & $1,21(0,46-3,17)$ & $1,21(0,45-3,23)$ \\
\hline $48.001+$ & 13 & 25,5 & 50 & 24,5 & $1,89(0,77-4,63)$ & $1,78(0,71-4,43)$ \\
\hline
\end{tabular}

IC95\%: intervalo de 95\% de confiança.

* Ajustada por sexo, idade e tempo de aplicação;

** Ajustada por sexo, idade, tempo de aplicação, etilismo, tabagismo e coexposição ocupacional a metais e/ou solventes.

Nota: significância estatística, $p<0,05$. 
Tabela 3

Razão de chances (OR) de tremor essencial entre guardas de endemias, segundo carga acumulada por grupo químico.

\begin{tabular}{|c|c|c|c|c|c|c|}
\hline \multirow[t]{2}{*}{ Carga acumulada por grupo químico (kg) } & \multicolumn{2}{|c|}{ Casos } & \multicolumn{2}{|c|}{ Controles } & \multirow[t]{2}{*}{ OR (IC95\%) * } & \multirow[t]{2}{*}{ OR (IC95\%) ** } \\
\hline & $\mathbf{n}$ & $\%$ & $\mathbf{n}$ & $\%$ & & \\
\hline \multicolumn{7}{|l|}{ Organofosforado *** } \\
\hline$\leq 1.100$ & 12 & 23,5 & 53 & 26,0 & \multicolumn{2}{|c|}{ Referência } \\
\hline $1.100,1-2.750$ & 12 & 23,5 & 53 & 26,0 & $1,19(0,47-3,03)$ & $1,13(0,43-2,96)$ \\
\hline $2.750,1-4.400$ & 16 & 31,4 & 52 & 25,5 & $0,95(0,38-2,38)$ & $0,87(0,34-2,22)$ \\
\hline $4.400,1+$ & 11 & 21,6 & 46 & 22,5 & $1,42(0,59-3,44)$ & $1,42(0,57-3,52)$ \\
\hline \multicolumn{7}{|l|}{ Organofosforado \# } \\
\hline$\leq 3,3$ & 14 & 27,5 & 55 & 27,0 & \multicolumn{2}{|c|}{ Referência } \\
\hline $3,3-7,7$ & 12 & 23,5 & 47 & 23,0 & $1,92(0,74-5,02)$ & $2,09(0,78-5,62)$ \\
\hline $7,71-9,9$ & 16 & 31,4 & 54 & 26,5 & $1,39(0,53-3,63)$ & $1,48(0,56-3,92)$ \\
\hline $9,91+$ & 9 & 17,6 & 48 & 23,5 & $1,67(0,66-4,21)$ & $1,77(0,68-4,60)$ \\
\hline \multicolumn{7}{|l|}{ Benzoilureia \#\# } \\
\hline$\leq 11$ & 14 & 51,9 & 58 & 63,0 & \multicolumn{2}{|c|}{ Referência } \\
\hline $11-22$ & 12 & 44,4 & 30 & 32,6 & $1,29(0,13-12,74)$ & $1,38(0,12-16,39)$ \\
\hline $22,1+$ & 1 & 3,7 & 4 & 4,4 & $1,80(0,18-18,36)$ & $1,86(0,16-21,53)$ \\
\hline
\end{tabular}

IC95\%: intervalo de 95\% de confiança.

* Ajustada por sexo, idade e tempo de aplicação;

** Ajustada por sexo, idade, tempo de aplicação, etilismo, tabagismo e coexposição ocupacional a metais e/ou solventes;

*** Malation (bomba costal 5L);

\# Temefós (granulado $1 / 2$ colher de sopa);

\#\# Diflubenzuron (garrafa PET).

Nota: significância estatística, $\mathrm{p}<0,05$.

Apesar do referido estudo também ter utilizado dois controles distintos, a presença de trabalhadores jovens e com pouco tempo de aplicação de agrotóxicos pode ter influenciado na ausência de associação significativa 39. Da mesma forma, em outro estudo, realizado entre agricultores sul-africanos 40 , também não foi observada associação entre tremor e exposição a agrotóxicos. Nesse estudo, apesar de utilizarem dois indicadores distintos para estimar a exposição acumulada a agrotóxicos, a pouca idade dos agricultores envolvidos e o baixo tempo de aplicação podem ter contribuído para a ausência de associação 40. Por fim, a exposição a agrotóxicos organoclorados também não esteve associada ao aumento de chance de tremor essencial em estudo caso-controle realizado em Manhattan, cidade de Nova York (Estados Unidos) 41.

Os resultados do presente estudo precisam ser interpretados à luz das potenciais limitações inerentes ao desenho adotado. Nesse sentido, a amostragem por conveniência, o tamanho reduzido da amostra, os possíveis erros de classificação não diferenciais, a utilização de controles também expostos a agrotóxicos são, por exemplo, algumas dessas limitações que podem ter acarretado distorções das estimativas de associação entre a exposição a agrotóxicos e tremor essencial.

Foi observado, neste estudo, um predomínio masculino em uma proporção de 2,7 homens para cada mulher. Esse predomínio masculino também foi observado nos estudos avaliados 38,39,40,41. É possível que a exigência física ainda influencie nessa proporção. Em média, a idade dos trabalhadores portadores de tremor essencial foi de 51 anos, e está abaixo da média da maioria dos estudos que avaliam essa doença 8,9,11,37,41. A precocidade da doença é um aspecto frequentemente encontrado em doenças ocupacionais. Os trabalhadores estudados eram bastante experientes e, em sua grande maioria, já haviam passado por inúmeras campanhas e múltiplas exposições químicas. No momento da confirmação diagnóstica, a maioria dos casos de tremor essencial era leve a moderado, com o tempo médio de início da doença de 5,3 anos, e poucos trabalhadores tinham a indicação de tratamento medicamentoso. 


\section{Tabela 4}

Razão de chances (OR) de tremor essencial entre guardas de endemias, segundo tempo de aplicação de agrotóxicos.

\begin{tabular}{|c|c|c|c|c|c|c|}
\hline \multirow[t]{2}{*}{ Tempo de exposição (anos) } & \multicolumn{2}{|c|}{ Casos } & \multicolumn{2}{|c|}{ Controles } & \multirow[t]{2}{*}{ OR (IC95\%) * } & \multirow[t]{2}{*}{ OR (IC95\%) ** } \\
\hline & $\mathbf{n}$ & $\%$ & $\mathbf{n}$ & $\%$ & & \\
\hline$\leq 13$ & 4 & 7,8 & 44 & 21,6 & \multicolumn{2}{|c|}{ Referência } \\
\hline $14-15,9$ & 13 & 25,5 & 27 & 1,23 & $0,94(0,21-4,23)$ & $1,03(0,22-4,81)$ \\
\hline $16-16,9$ & 7 & 13,7 & 29 & 14,2 & $4,60(1,29-16,41)$ & $4,91(1,34-18,03)$ \\
\hline $17-17,9$ & 7 & 13,7 & 25 & 12,3 & $2,32(0,59-9,03)$ & $2,50(0,61-10,23)$ \\
\hline $18-20,9$ & 9 & 17,6 & 29 & 14,2 & $2,44(0,63-9,44)$ & $2,39(0,59-9,66)$ \\
\hline $21-24,9$ & 7 & 13,7 & 20 & 9,8 & $2,57(0,71-9,33)$ & $2,71(0,72-10,87)$ \\
\hline$\geq 25$ & 4 & 7,8 & 30 & 14,7 & $2,81(0,72-10,91)$ & $3,03(0,75-12.27)$ \\
\hline
\end{tabular}

IC95\%: intervalo de 95\% de confiança.

* Ajustada por sexo e idade;

** Ajustada por sexo, idade, etilismo, tabagismo e coexposição ocupacional a metais e/ou solventes.

Nota: significância estatística, $p<0,05$.

O tempo de aplicação de inseticidas/larvicidas $\geq 11$ anos e a coexposição ocupacional a metais e/ ou solventes foram aspectos ocupacionais relevantes para a doença. Já o alcoolismo, tem conhecido efeito deletério sobre o sistema nervoso central e periférico. Casos de alcoolismo foram excluídos da amostra. Semelhante a outros resultados na literatura, observamos que o etilismo estava associado ao tremor essencial 42,43. A literatura ainda discute o real papel do etilismo social para essa doença, haja vista que clinicamente pequenas doses de álcool podem minimizar o tremor e, nos primórdios dos critérios de classificação, era considerado um sinal clínico para o seu diagnóstico 42,43. Foi observado um potencial efeito protetor do tabagismo nos trabalhadores portadores de tremor essencial. Esse efeito protetor é corroborado pela literatura vigente 44 . Em modelo experimental de parkinsonismo em ratos, a nicotina apresentou-se como protetor neuronal por meio da indução de fatores neurotróficos 45 .

A quantidade de horas aplicadas de inseticidas e larvicidas ( $\geq 33.001$ horas) também apresentou importante relação com o tremor essencial. A utilização de índices como horas, dias-acumulados e cargas aplicadas para estimar exposições, especialmente as ocupacionais, é uma técnica eficaz e comumente empregada em estudos dessa natureza 37,40,46,47,48. Apesar da ausência de significância estatística da OR de tremor essencial dos modelos apresentados entre casos e controles (Tabelas 2 e 3), possui potencial promissor para a estimativa de gradiente dose-resposta e, ao mesmo tempo, agrega conceitos clínicos e toxicológicos básicos para a compreensão dos fenômenos envolvidos.

O aumento na OR de tremor essencial em função do tempo de aplicação de agrotóxicos mostrou-se mais evidente entre aqueles trabalhadores com 16 e 16,9 anos de aplicação, coincidindo com o período em que foram utilizados inseticidas e larvicidas do grupo químico organofosforado. Considerando os resultados de estudos em modelo animal, estudos clínicos e toxicológicos desses agentes, é possível que haja um sinergismo entre os diversos grupos químicos de agrotóxicos no desenvolvimento do tremor essencial. Todavia, não é possível afirmar com o desenho empregado a exposição combinada a outras classes de agrotóxicos, tampouco os “ingredientes inertes” presentes em sua composição.

\section{Conclusões}

Considerando a amostra da população de guardas de endemias lotados no Estado do Rio de Janeiro, avaliada entre agosto de 2010 e setembro de 2012, concluímos que o tempo de aplicação de agrotóxicos pode estar associado ao desenvolvimento de tremor essencial nessa categoria profissional. 


\section{Colaboradores}

M. F. A. Azevedo participou da concepção e projeto do estudo, análise e interpretação dos dados, redação do artigo, aprovação final da versão, responsável pela garantia da exatidão e integridade da obra. A. Meyer participou da concepção e projeto do estudo, revisão crítica relevante do conteúdo intelectual e aprovação da versão final.

\section{Referências}

1. Sindicato Nacional das Indústrias de Defensivos Agrícolas. Vendas de defensivos agrícolas são recordes e vão a US\$ 8,5 bi em 2011. http://www.sindag.com.br/noticia.php? News_ID=2256 (acessado em 22/Abr/2012).

2. Agência Nacional de Vigilância Sanitária. Seminário de mercado de agrotóxico e regulação. http://portal.anvisa.gov.br/wps/content/ anvisa+portal/anvisa/sala+de+imprensa/ menu+noticias+anos/2012+noticias/semina rio+volta+a+discutir+mercado+de+agrotoxi cos+em+2012 (acessado em 11/Abr/2012).

3. Ministério da Saúde; Organização Pan-Americana da Saúde. Manual de vigilância da saúde de populações expostas a agrotóxicos. http:// bvsms.saude.gov.br/bvs/publicacoes/livro2. pdf (acessado em 18/Set/2010).

4. Agência Nacional de Vigilância Sanitária. Resolução-RDC no 34, de 16 de agosto de 2010. Dispõe sobre o Regulamento Técnico para produtos saneantes desinfestantes. Diário Oficial da União 2010; 18 ago.

5. Agência Nacional de Vigilância Sanitária. Resolução-RDC no 52, de 22 de outubro de 2009. Dispõe sobre o funcionamento de empresas especializadas na prestação de serviço de controle de vetores e pragas urbanas e dá outras providências. Diário Oficial da União 2009; 26 out.

6. Raethjen J, Deuschl G. Tremor. Curr Opin Neurol 2009; 22:400-5.

7. Louis ED, Ferreira JJ. How common is the most common adult movement disorder? Update on the worldwide prevalence of essential tremor. Mov Disord 2010; 25:534-41.

8. Louis ED, Thawani SP, Andrews HF. Prevalence of essential tremor in a multiethnic, community-based study in Northern Manhattan, New York, N.Y. Neuroepidemiology 2009; 32:208-14.

9. LaRoia H, Louis ED. Association between essential tremor and other neurodegenerative diseases: what is the epidemiological evidence? Neuroepidemiology 2011; 37:1-10.

10. Louis ED. Essential tremor. Lancet Neurol 2005; 4:100-10.

11. Barbosa MT, Caramelli P, Cunningham MCQ, Maia DP, Lima-Costa MFF, Cardoso F. Prevalence and clinical classification of tremor in elderly: a community-based survey in Brazil. Mov Disord 2013; 28:640-6.

12. Duss P. Cerebelo. In: Baehr M, Frotscher M, organizadores. Diagnóstico topográfico em neurologia. 4a Ed. Rio de Janeiro: Editora Guanabara Koogan; 1997. p. 147-56.

13. Machado ABM. Grandes vias eferentes. In Haertel LM, Machado A, organizadores. Neuroanatomia funcional. Rio de Janeiro: Editora Atheneu; 1974. p. 254-62.

14. Lent R. Cem bilhões de neurônios: conceitos fundamentais de neurociência. Rio de Janeiro: Editora Atheneu; 2004. 
15. Wilms H, Sievers J, Deuschl G. Animal models of tremor. Mov Disord 1999; 14:557-71.

16. Yahr MD, Orosz D, Purohit DP. Co-occurrence of essential tremor and Parkinson's disease: clinical study of a large kindred with autopsy findings. Parkinsonism Relat Disord 2003; 9:225-31.

17. Louis ED, Okun MS. It is time to remove the 'benign' from the essential tremor label. Parkinsonism Relat Disord 2011; 17:516-20.

18. Lorenz D, Deuschl G. Update on pathogenesis and treatment of essential tremor. Curr Opin Neurol 2007; 20:447-52.

19. Thier S, Kuhlenbäumer G, Lorenz D, Nothnagel M, Nebel A, Christensen K, et al. GABAA receptor- and GABA transporter polymorphisms and risk for essential tremor. Eur J Neurol 2011; 18:1098-100.

20. Alonzo HGA, Corrêa CL. Praguicidas. In: Oga S, Camargo MMA, Batistuzzo JAO, organizadores. Fundamentos da toxicologia. 3a Ed. Rio de Janeiro: Editora Atheneu; 2008. p. 621-42.

21. Costa LG. Toxic effects of pesticides. In: Klaassen DC, editor. Casarett and Doull's toxicology: the basic science of poisons. 7th Ed. New York: McGraw-Hill; 2008. p. 883-930.

22. Braga IA, Valle D. Aedes aegypti: inseticidas, mecanismos de ação e resistência. Epidemiol Serv Saúde 2007; 16:279-93.

23. Borges RA, Arruda W, Oliveira ESF, Cavasin GM, Silva HHG, Silva IG. Mecanismos da ação larvicida do diflubenzuron sobre Aedes aegypti evidenciados pelas alterações ultraestruturais. Rev Patol Trop 2012; 41:222-32.

24. Androutsopoulos VP, Hernandez AF, Liesivuori J, Tsatsakis AM. A mechanistic overview of health associated effects of low levels of organochlorine and organophosphorous pesticides. Toxicology 2013; 307:89-94.

25. Hernández AF, Lacasaña M, Gil F, RodríguezBarranco M, Pla A, Lópes-Guarnido O. Evaluation of pesticide-induced oxidative stress from a gene-environment interaction perspective. Toxicology 2013; 307:95-102.

26. Clark LN, Park N, Kisselev S, Rios E, Lee JH, Louis ED. Replication of the LINGO1 gene association with essential tremor in a North American population. Eur J Hum Genet 2010; 18:838-43.

27. Mostafalou S, Abdollahi M. Pesticides and human chronic diseases: evidences, mechanisms, and perspectives. Toxicol Appl Pharmacol 2013; 268:157-77.

28. Deuschl G, Bain P, Brin M. Consensus statement of the Movement Disorder Society on Tremor. Ad Hoc Scientific Committee. Mov Disord 1998; 13 Suppl 3:2-23.

29. Hess CW, Pullman SL. Tremor: clinical phenomenology and assessment techniques. Tremor Other Hyperkinet Mov (NY) 2012; 2:tre-02-65-365-1.

30. Louis ED. Environmental epidemiology of essential tremor. Neuroepidemiology 2008; $31: 139-49$
31. Faff J, Borkowska G, Bak W. Therapeutic effects of some cholinolytics in organophosphate intoxications. Arch Toxicol 1976; 36:139-46.

32. Verschoyle RD, Aldridge WN. Structure-activity relationships of some pyrethroids in rats. Arch Toxicol 1980; 45:325-9.

33. Tilson HA, Hong JS, Mactutus CF. Effects of 5,5-diphenylhydantoin (phenytoin) on neurobehavioral toxicity of organochlorine insecticides and permethrin. J Pharmacol Exp Ther 1985; 233:285-9.

34. Gershon S, Shaw FH. Psychiatric sequelae of chronic exposure to organophosphorus insecticides. Lancet 1961; 1:1371-4.

35. Taylor JR, Selhorst JB, Houff SA, Martinez AJ. Chlordecone intoxication in man. I. Clinical observations. Neurology 1978; 28:626-30.

36. Miyamoto J, Kaneko H, Tsuji R, Okuno Y. Pyrethroids, nerve poisons: how their risks to human health should be assessed. Toxicol Lett 1995; 82-3:933-40.

37. Kamel F, Engel LS, Gladen BC, Hoppin JA, Alavanja MCR, Sandler DP. Neurologic symptoms in licensed private pesticide applicators in the Agricultural Health Study. Environ Health Perspect 2005; 113:877-82.

38. Davignon LF, St-Pierre J, Charest TC, Tourangeau FJ. A study of the chronic effects of insecticides in man. Can Med Assoc J 1965; 92:597-602.

39. Steenland K, Dick RB, Howell RJ, Chrislip DW, Hines C, Reid TM, et al. Neurologic function among termiticide applicators exposed to chlorpyrifos. Environ Health Perspect 2000; 108:293-300.

40. London L, Nell V, Thompson ML, Myers JE. Effects of long-term organophosphate exposures on neurological symptoms, vibration sense and tremor among South African farm workers. Scand J Work Environ Health 1998; 24:18-29.

41. Louis ED, Factor-Litvak P, Parides M, Andrews L, Santella RM, Wolff MS. Organochlorine pesticide exposure in essential tremor: a case-control study using biological and occupational exposure assessments. Neurotoxicology 2006; 27:579-86.

42. Louis ED, Benito-León J, Bermejo-Pareja F. Population-based study of baseline ethanol consumption and risk of incident essential tremor. J Neurol Neurosurg Psychiatry 2009; 80:494-7.

43. Mostile G, Jankovic J. Alcohol in essential tremor and other movement disorders. Mov Disord 2010; 25:2274-84.

44. Louis ED, Benito-León J, Bermejo-Pareja F. Population-based prospective study of cigarette smoking and risk of incident essential tremor. Neurology 2008; 70:1682-7. 
45. Maggio R, Riva M, Vaglini F. Nicotine prevents experimental parkinsonism in rodents and induces striatal increase of neurotrophic factors. J Neurochem 1998; 71:2439-46.

46. Rigolin GM, Cuneo A, Roberti MG, Bardi A, Bigoni R, Piva N, et al. Exposure to myelotoxic agents and myelodysplasia: case-control study and correlation with clinicobiological findings. Br J Haematol 1998; 103:189-97.

\section{Abstract}

Tremor is the most frequent movement disorder in the population and can be associated with pesticide exposure. The aim was to assess the odds of essential tremor in 442 endemic disease control agents in Rio de Janeiro State, Brazil, exposed to pesticides. Fifty-one cases and 204 controls were selected (1:4). All participants answered a questionnaire on socio-demographic, occupational, and toxicological items. The influence of pesticide exposure on the development of tremor was estimated by non-conditional logistic regression, adjusted for selected covariables. Mean age of the study population was $49(S D=7)$ years, and the difference between cases (mean $=50.8 ; S D=6.9)$ and controls (mean $=48.5 ; S D=6.9)$ was statistically significant $(p=0.03)$. Those with 16 to 16.9 years of pesticide use showed the highest odds of essential tremor (adjusted OR = 4.60; 95\%CI: 1.29-16.41). Our results suggest that 16 to 16.9 years of pesticide exposure had a major impact on the development of essential tremor.

Essential Tremor; Agrochemicals; Organophosphorus Compounds
47. Rodríguez T, Joode BW, Lindh CH, Rojas $\mathrm{M}$ Lundberg I, Wesseling C. Assessment of longterm and recent pesticide exposure among rural school children in Nicaragua. Occup Environ Med 2012; 69:119-25.

48. Kivimäki M, Jokela M, Nyberg ST, Singh-Manoux A, Fransson EI, Alfredsson L, et al. Long working hours and risk of coronary heart disease and stroke: a systematic review and meta-analysis of published and unpublished data for 603,838 individuals. Lancet 2015 386:1739-46.

\section{Resumen}

El temblor es el disturbio de movimiento más frecuente en la población y puede estar asociado a la exposición a pesticidas. El objetivo fue evaluar la oportunidad del temblor esencial en 442 empleados públicos del sector de endemias del estado de Río de Janeiro, Brasil, expuestos a pesticidas. Se seleccionaron 51 casos y 204 controles (1:4). Todos los participantes respondieron a un cuestionario sobre aspectos sociodemográficos, ocupacionales $y$ toxicológicos. La influencia de la exposición a pesticidas sobre el desarrollo del temblor fue estimada por regresión logística no condicional, ajustada por covariables seleccionadas. La edad media de la población estudiada fue de $49(D P=7)$ años, siendo la diferencia entre casos (media $=50,8 ; D P=$ 6,9) y controles (media $=48,5 ; D P=6,9$ ) estadisticamente significativa $(p=0,03)$. Además, aquellos de 16 a 16,9 años de servicio de fumigación con pesticidas fueron los que estuvieron bajo la mayor oportunidad de presentar la enfermedad (OR ajustada = 4,60; IC95\%: 1,29-16,41). Nuestros resultados sugieren que el período entre 16 y 16,9 años de fumigación con pesticidas tuvo un impacto importante para el desarrollo de esa enfermedad.

Temblor Esencial; Agroquímicos;

Compuestos Organofosforados
Recebido em 26/Nov/2015

Versão final reapresentada em 15/Out/2016 Aprovado em 25/Out/2016 